\title{
Assessment of Environmental Impact for Tannery Industries in Bangladesh
}

\author{
Abul Hasnat, Istiakur Rahman, and Mosabbir Pasha
}

\begin{abstract}
Leather industry is a prominent industrial sector in Bangladesh which has a massive influence on our economy. The industry has become an area of export thrust with footwear having been identified as an area of extreme focus. Though having massive potential, this overgrowing sector has received much criticism on environmental as well as health issue. Basically the process of tanning is to retain the skin's natural properties, to stabilize its structure and at the same time to chemically process it so it will no longer be subject to putrefaction. It is one of the most energy intensive industries in Bangladesh which creates eco toxicity like water pollution, solid waste generations. In Bangladesh eco toxicity evaluation of any aquatic environment has not been conducted in large scale so far. Tannery discharge wastes to the marshy land like rivers and canals which carry toxic chemical like $\mathrm{H}_{2} \mathrm{~S}$ (water), $\mathrm{NH}_{3}$ (ammonia), poisonous chlorine and nitrogen based gases. According to a report by SOCIETY FOR ENVIRONMENT AND HUMAN DEVELOPMENT (SEHD), millions of people suffer from gastrointestinal, dermatological and other diseases and $90 \%$ of them die before the age of 50 . This project has been done to focus on the evaluation of pollution on the relative areas and also aimed at optimum utilization of for this Environmental Impact Assessment (EIA) has been done in those particular areas. It shows highly negative impact on ecological environment but shows more positive impact on human interest.
\end{abstract}

Index Terms-EIA, eco toxicity, optimum utilization, tannery discharge, water treatment.

\section{INTRODUCTION}

Bangladesh is one of the largest deltas in the world consisting of 230 rivers and rivulets and coastline of 710 kilometers having a unique diversity of ecosystem. Bangladesh is identified as a zone of multiple vulnerability, prone to severe natural and artificial disasters. Industrial activities produce industrial waste. But it becomes hazardous when it's not properly manipulated. Tannery disposals are rancid higher pollutants among industrial wastes. Bangladesh has goodwill worldwide in exporting tanning products due to their auspicious quality. There are 214 tanneries in Bangladesh, among them 200 are in Dhaka city and rest 14 are scattered all over the country. Among the manufacturing sectors, the tanning industry comes as the leading exporter and accounting for up to $6 \%$ of the total manufactured exports [1]. Export earnings from the leather industries sector in 1995-1996 was USD \$237.79 million, of which USD \$211.70 million was from leather exports and USD \$26.09 million was from export of finished leather products [1].

Manuscript received December 9, 2012; revised February 5, 2013.

Abul Hasnat, Istiakur Rahman, and Mosabbir Pasha are with the Department of CEE, Islamic University of Technology (IUT), Bangladesh (email: mosabbirpasha@yahoo.com).
These industries process 220 metric tons of hide a day and some 40 to 50 liter of chemical liquids for each kilogram of hide [2]. However the industrial establishments' huge potential of for sustained economic development of the country has been constrained for they were not designed and operated in sustainable manner. Most of the tanneries do not have treatment facilities and environment management systems, as a result simply discharging their wastes into the environment. Thus, are causing serious environmental and public health problems in particular areas. So this sector cannot survive unless appropriate environmental management is induced. So a study was undertaken to improve the environmental performance and consequently the productivity of our tanneries.

\section{OBJECTIVES}

1) To provide actual scenario of impact of tannery waste on environment

2) To ensure sustainability of tanneries development

3) To identify the source of safe production, managing adverse impacts

4) To enforce environmental policy and applicable environmental legislations.

\section{Methodology}

The study was overtaken by several following tasks:

1) Visiting tanneries and respective surrounding places

2) On-site assessments and interviews with relevant personnel

3) Preparing EIA report based on interviews

To stipulate the promotion of waste minimization by suggesting mitigation measures.

\section{A. Study Area}

The study was conducted in Madina tannery, which is the largest tannery in Chittagong. It is situated at Jalalabad area near Oxygen point. The study area is located at 22 23'14.36" N latitude and $9149^{\prime} 14.36$ " E longitudes, elevation is 41 feet. It was established in 1983. Madina tannery is renowned for manufacturing all sorts of crust and finished leather and exports them to America and Europe. A refinery industry is situated at the south direction of the industry. There are some crop fields and isolated residential houses in the direction of north boundary. Within the $1 \mathrm{~km}$ of Madina tannery, urban development is considerably observed. In the back of the tannery, there is a railway line after which there are hillocks in north south direction. Seasonal, intermittent and perennial streams are introduced in the drainage system of the area. The 
annual average rainfall is recorded $2870 \mathrm{~mm}$ (113in). By runoff, all the wastes are drained and affect the nearby agricultural field. [3].

\section{B. Tanning Process}

It is a process of converting putrescible animal hides and skins to a stable commercial product called "Leather". Card hides and skins arriving at a tannery are trimmed to remove unwanted materials for making of leather. Then the soaking, liming, fleshing, de-liming, bating degreasing and pickling processes are carried out to create a favorable environment for tanning process.

\section{Impact on Environment}

Tanning process includes both solid and liquid wastes. The solid wastes are predominantly from the initial and final stages of processing while the effluents are produced mostly during tanning and dying. The effluents contain dissolved lime, hydrogen sulfide, acids, chromium dyes, oils, organic matter and suspended solids. The waste water which is discharged into open drains and ultimately find its way onto land surfaces and into waters in the vicinity. As it is difficult to flush-out the waste water, so it causing a great environmental hazard in the neighborhood of the tannery. On the other hand, dumping of solid waste is seriously affecting the soil and plants, vitiating the air, groundwater and human health.

\section{ENVIRONMENTAL IMPACT ASSESSMENT}

Environmental Impact Assessment (EIA) is the assessment of the changes in environmental resources or values resulting industry or project which may be positive or negative. The EIA process generally comprises of three sequential elements:

1) All potential positive and negative impacts on the natural and human environment resulting from a project which is going to occur in future or may exist at present as an industry or a project.

2) Evaluation of the identified impacts with respect to impacts from other industrial actions.

3) Preparation of a mitigation plan which upon implementation will reduce negative impacts on the environment to acceptable levels.

\section{A. Method of Assessment}

Considering the situation prevailing in the country and to be definitive in work, a simple methodology was taken for Environmental Impact Assessment. The methodology is based on Environmental Evaluation System (EES) as the assessment is not done for such a project which is going to be established in future. In Bangladesh, in the absence of a data base it is only possible to estimate the potential environmental changes from the existing situation. In this method, the background environmental conditions were the reference level and the positive and negative changes in environmental conditions resulting from the Tannery industries were evaluated. Environmental impact assessed by Environmental Impact Values (EIVs). The mathematical definition of EIVs is given by the equation (1):

$$
E I V=\sum_{i=0}^{n} V i W i
$$

where

$V i$, Relative change in the value of environmental quality of parameter $i$ with respect to existing situation.

$W i$, Relative importance or weight of parameter $i$. It represents relative weight or importance of the respective parameters.

$n$, Total number of environmental parameter related to the project.

The computation of Environmental Impact Value (EIV) needs determination of $V i$, the value representing the magnitude of alteration of the environmental parameters, and $W i$, the value representing relative weight or importance of the respective parameters.

\section{B. Magnitude of Environmental Alterations}

The positive and negative changes in environmental parameters resulting from tannery industries, usually expressed in qualitative terms. Since the changes of environmental parameters are measured with respect to background conditions, no change has 0 values. The adverse changes have been given values $-1,-2,-3$ and -4 to represent low, moderate, high and severe negative impacts respectively. Similarly $+1,+2,+3$ and +4 represent low, moderate, high and very high positive impacts respectively. The EIV of the tannery was computed by taking a value from the scale representing effect of the project on each parameter.

\section{Relative Importance of Environmental Parameters}

All environmental parameters influenced by the Tanneries are not of equal importance. The importance of a parameter varies from country to country depending on the environmental concerns of the country and the parameters that influence human life and aquatic lives directly. In Bangladesh, flood, employment, agriculture, fisheries, etc. carry more importance than many others. The parameters related to tanneries were given different values based on prevailing environmental concerns in Bangladesh and are presented in Table I. The values representing importance or weight of the parameters can be used to compute the relative impacts of the parameters which are then summed up to obtain the total EIV of Madina Tannery. However this method has following significant drawbacks [4].

1) The input judgments are not quantified efficiently.

2) It does not consider the consistency of judgments.

3) Only neighboring parameters in the list are directly compared.

The values indicating magnitude of environmental changes and corresponding importance of environmental parameters influenced by the tanneries were placed in the appropriate columns in Table I and then multiplied them to obtain positive and negative impact of the parameters. Finally all these impacts as illustrated in Table I were summed up to obtain the total EIV.

\section{RESUlTS AND DisCUSSION}

As we get the total environmental impact value (EIV) from table I is -133. Some of the human interest factors were found positive but all the other physic-chemical factors made the 
total EIV negative.

Based on the survey the physical impact was found -47. It is because of discharging the waste water without proper treatment. For this reason surface water quality is becoming polluted as well as the ground water. Also the air quality is degrading in an alarming rate. Those who live near the tanneries face severe problem for sound pollution.

Fish culture becomes wiped out near the tannery area due to discharge of untreated waste water into the water body. Growth of trees reduces and sometimes the soil loses its fertility.

Due to tanneries different types of industries are built near the tannery zone. The human interest has a positive impact because employment increases very rapidly although the sewage system becomes ineffective for the clogged water.

\begin{tabular}{|c|c|c|c|c|c|}
\hline \multirow[t]{2}{*}{ Parameter } & \multirow{2}{*}{$\begin{array}{l}\text { Relative } \\
\text { importa } \\
\text { nce } \\
\text { value }\end{array}$} & \multirow{2}{*}{$\begin{array}{l}\text { Degree } \\
\text { of } \\
\text { impact }\end{array}$} & \multicolumn{2}{|c|}{ Relative impact } & \multirow[b]{2}{*}{ EIV } \\
\hline & & & Positive & Negative & \\
\hline 1. Physical & & & & & -47 \\
\hline $\begin{array}{l}\text { Ground } \\
\text { water } \\
\text { pollution }\end{array}$ & 2 & -2 & & -4 & \\
\hline Soil fertility & 3 & -3 & & -9 & \\
\hline $\begin{array}{l}\text { Surface } \\
\text { water } \\
\text { Pollution } \\
\end{array}$ & 3 & -5 & & -15 & \\
\hline $\begin{array}{l}\text { Air } \\
\text { pollution }\end{array}$ & 3 & -3 & & -9 & \\
\hline $\begin{array}{l}\text { Noise } \\
\text { pollution }\end{array}$ & 2 & -5 & & -10 & \\
\hline $\begin{array}{l}2 . \\
\text { Ecological }\end{array}$ & & & & & -20 \\
\hline Fisheries & 2 & -4 & & -8 & \\
\hline Forest & 2 & -5 & & -10 & \\
\hline Wild life & 1 & -2 & & -2 & \\
\hline $\begin{array}{l}\text { 3. Human } \\
\text { interest }\end{array}$ & & & & & +7 \\
\hline $\begin{array}{l}\text { Loss of } \\
\text { agricultural } \\
\text { lands }\end{array}$ & 1 & -2 & & -6 & \\
\hline $\begin{array}{l}\text { Industrial } \\
\text { activities }\end{array}$ & 3 & +2 & +6 & & \\
\hline $\begin{array}{l}\text { Employment } \\
\text { opportunities }\end{array}$ & 6 & +5 & +30 & & \\
\hline Recreation & 1 & -3 & & -9 & \\
\hline Sewage & 2 & -7 & & -14 & \\
\hline $\begin{array}{l}\text { 4. Quality of } \\
\text { life }\end{array}$ & & & & & -73 \\
\hline Aesthetics & 3 & -1 & & -3 & \\
\hline Health & 3 & -9 & & -27 & \\
\hline Solid waste & 4 & -7 & & -28 & \\
\hline Safety & 3 & -5 & & -15 & \\
\hline Total EIV & & & & & -133 \\
\hline
\end{tabular}

During the study it was found that solid wastes were dumped in open places which create the most severe problem for the environment. It was also found that the workers do not take any kind of safety measures during the work hour. People those who live near the tannery industries and works there suffers from different diseases.

Despite all of that the most severe problem was found that there is lack of proper guideline. A multi-donor program called Flood Action Plan (FAP) was undertaken after the 1987-88 floods. As part of the FAP studies the guideline for Environmental Impact Assessment was prepared in 1992. The manual for Environmental Impact Assessment was prepared in 1995. This was the first attempt to identify the environmental impacts of development activities in Bangladesh. But they are still in use for medium and large scale projects in water sector. So it is really a matter of great regret for industrial sectors in Bangladesh that there is such specific guideline to select parameters and assigning importance value to conduct EIA. For this reason some judgement was introduced here. In future some of these parameters from this study could be used for further EIA study for similar industrial sectors.

\section{Mitigation MEAsures}

As we can understand that the adverse effects of the tannery industries are very severe but considering its economical benefits we should not ignore this sector. To reduce the adverse effects for a sustainable environment the following steps should be taken immediately.

For waste water treatment every tannery should establish Effluent Treatment Plant (ETP).

1) There should be a particular industrial zone for tannery industries far enough from the residential area.

2) There should be a particular industrial zone for tannery industries far enough from the residential area.

3) The treated waste water discharged from the industries should be within the acceptable limit according to the Environmental Conservation Rule '97 (ECR '97), which must be monitored by the government officials.

4) Solid waste should be disposed very carefully in a particular zone.

5) Safety of workers must be ensured.

6) Wastes that are used for poultry food must be free from certain chemicals specially chromium.

7) Environmental Management Plan should be introduced for reducing pollution and make the process more compatible with environmental sustainability.

8) Before establishing any industries the resettlement plan for the affected people must be considered.

\section{REFERENCES}

[1] S. M. Imamul Huq, "Critical Environmental Issues Relating to Tanning Industries in Bangladesh,” pp. 22, February, 1998.

[2] K. M. Shams, G. Tichy, M. Sager, T. Peer, A. Bashar, and M. Jozic, "Soil Contamination From Tannery Wastes with Emphasis on the Fate and Distribution of Tri- and Hexavalent," vol. 26, pp. 123-124, September 2008

[3] K. M. N. Islam1, K. Misbahuzzamanl, A. K. Majumder, and M Chakrabarty, "Efficiency of different coagulants combination for the treatment of tannery effluents: A case study of Bangladesh," African Journal of Environmental Science and Technology, vol. 30, pp. 410, May, 2011.

[4] N. Dee, J. Baker, N. Drobny, K. Duke, T. Whitman, and P. Fahringer, "An Environmental Evaluation System for Water Resource Planning," Water Resource Research, vol. 9, pp. 523-535, 1972.

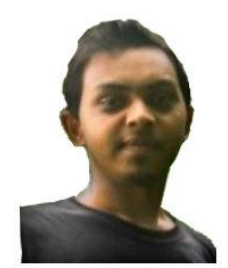

Abul Hasnat is now in Civil and Environmental Engineering Department of Islamic University of Technology (IUT), Gazipur, Bangladesh. His main research interests are Structure,Waste Water Treatment,Solid Waste Management, Landfill Leachate management, Water Resource Management. 


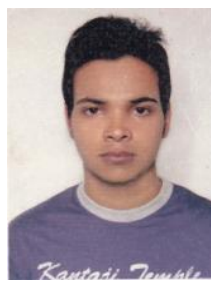

Istiakur Rahman is now in Civil and Environmental Engineering Department of Islamic University of Technology (IUT), Gazipur, Bangladesh. His main research interests are Structure,Renewable energy,Waste Water Treatment, Environmental Chemistry, Solid Waste Management, Landfill Leachate management, Climate Change, Water Resource Management.
Mosabbir Pasha is with Civil and Environmental Engineering Department of Islamic University of Technology (IUT), Gazipur, Bangladesh. His main research interests are Waste Water Treatment, Environmental Chemistry, Solid Waste Management, Landfill Leachate management, Climate Change, Water Resource Management. 